\title{
Gaya pengajaran Grasha dalam kalangan pensyarah sains di Kolej Pra-Universiti di Pulau Pinang
}

\author{
Anis Humaira Mohamad Marzuki ${ }^{1 *}$, Nurhazwani Mhod Shukri², Hafsah Taha ${ }^{3}$ \\ Faculty of Sciences and Mathematics, Sultan Idris Education University, \\ Tanjong Malim, Perak, Malaysia \\ *email: anishumaira1994@gmail.com
}

DOI: https://doi.org/10.37134/jpsmm.vol9.2.3.2019

Published: 07 December 2019

\begin{abstract}
Abstrak
Kemerosotan pelajar dalam bidang STEM di Malaysia pada masa kini amat membimbangkan. Kolej matrikulasi sebagai kolej pra-universiti memainkan peranan yang penting dalam memupuk dan mengekalkan minat pelajar dalam bidang tersebut. Justeru, peranan pensyarah sains sangat penting untuk memberikan penyampaian P\&P yang terbaik kepada pelajar. Oleh itu, kajian ini dijalankan untuk mengenalpasti gaya pengajaran yang diamalkan dalam kalangan pensyarah sains di kolej pra-universiti di Pulau Pinang. Kajian ini merupakan kajian kuantitatif den menggunakan reka bentuk kajian tinjauan. Soal Selidik Gaya Pengajaran Grasha-Riechmann 1994 yang mengandungi 40 item digunakan sebagai instrumen kajian. Hasil dapatan kajian mendapati gaya pengajaran dominan pensyarah subjek sains adalah gaya pengajaran pakar, diikuti gaya pengajaran model peribadi, gaya pengajaran fasilitator dan gaya pengajaran delegator. Manakala gaya pengajaran autoriti formal merupakan gaya yang paling kurang diamalkan oleh pensyarah. Analisis Spearman's-rho pula mendapati tidak terdapat hubungan yang signifikan di antara gaya pengajaran dengan pengalaman mengajar $(r=0.089)$, dan kelayakan ikhtisas $(r=0.193)$. Selain itu, ujian Mann-Whitney U melaporkan tiada perbezaan signifikan antara gaya pengajaran dengan jantina $(\mathrm{p}>0.05)$.
\end{abstract}

Kata kunci: gaya pengajaran Grasha, pra-universiti, STEM, pensyarah sains, matrikulasi

\section{Grasha Teaching Style Among Lecturers In Penang Pre-University College}

\begin{abstract}
Nowadays, the negative trend in students' enrolment in STEM related field caught the attention of many. As the main pre-university college in Malaysia, matriculation college play a vital role in nurturing and enhancing students' interest in that particular field. Thus, the role of science lecturer at matriculation college is important to deliver quality teaching to the students. This research is intended to explore the teaching style being practice among science lecturer in pre-university college in Penang. This research employed a quantitative approach with a survey design. The Grasha-Riechman Teaching Style Instrument 1994 that consist 40 items was used as the research instrument. The finding suggest that the expert teaching style is the most dominant style practice by respondent and followed by personal model teaching style, facilitator, and delegator teaching style. However, the formal authority teaching style is the least practiced style. On the other hand, Spearman's-rho correlation analysis suggests that there is no or very weak relationship between teaching style and teaching experience $(r=$ $0.089)$ and also between teaching style and education qualification $(r=0.193)$. Finding from MannWhitney $U$ test also suggest that there is no significant difference between teaching style and gender as $p>0.05$.
\end{abstract}

Keywords: Grasha teaching style, pre-university, STEM, science lecturer, matriculation 


\section{PENGENALAN}

Statistik enrolmen pelajar dalam bidang Sains, Teknologi, Kejuruteraan dan Matematik (STEM) di Malaysia melaporkan pola penurunan yang semakin membimbangkan. Menteri Pendidikan Malaysia, Dr. Maszlee Malik dalam ucapan beliau pada Sidang Kemuncak Kepimpinan Asia Bett dan Ekspo 2019 menyatakan terdapat kemerosotan peratusan pelajaran dalam bidang STEM iaitu daripada 49\% pada tahun 2012 kepada 44\% pada tahun 2018 (Salhani, 2019). Peratusan ini membawa kepada kemerosoton hampir 6000 orang pelajar setahun. Hal ini secara tidak langsung menyumbang kepada kekurangan jumlah pelajar dalam bidang STEM di institusi pengajian tinggi iaitu seramai 334742 orang berbanding 570858 pelajar dalam bidang bukan STEM (Wan Faizal, 2019).

Fenomena kemerosoton pelajar dalam bidang STEM adalah tidak sejajar dengan Pelan Pembangunan Pendidikan Malaysia yang mensasarkan untuk menarik minat dan kesedaran masyarakat dalam bidang STEM dalam gelombang kedua pada sela tahun 2016 2020 (Pelan Pembangunan Pendidikan Malaysia 2013-2025, 2013). Menjangkakan keperluan masa depan dalam bidang STEM, kerajaan pada tahun 1998 telah mewujudkan kolej matrikulasi Kementerian Pendidikan Malaysia (KPM) sebagai kolej pra-universiti dengan fokus utama untuk menyediakan pelajar bumiputera lepasan Sijil Pelajaran Malaysia (SPM) bagi menyambung pelajaran dalam bidang STEM dan perakaunan di institusi pengajian tinggi dalam dan luar negara. Dasar Pendidikan Kebangsaan menyatakan bahawa program matrikulasi KPM merupakan platform bagi membangunkan potensi pelajar bumiputera melalui pendidikan pra-universiti yang berkualiti untuk melayakkan mereka menyambung pelajaran ke peringkat yang lebih tinggi dalam bidang STEM dan profesional (Bahagian Perancangan dan Penyelidikan Dasar Pendidikan, 2017).

Meskipun telah banyak usaha yang dijalankan oleh kerajaan untuk meningkatkan minat pelajar dan masyarakan dalam bidang STEM, namun pola kemerosotan tetap berlaku. Antara faktor yang menyumbang kepada kemerosotan pelajar dalam aliran sains dapat dilihat daripada pelbagai aspek seperti pelajar, guru, kepimpinan sekolah, pentaksiran dan juga demografi sekolah (Fatin, Mohd Salleh, Mohammad Bilal, \& Salmiza, 2014). Bagi pelajar, kaedah dan amalan PdPc memberi kesan langsung kepada persepsi dan kerisauan mereka dalam menguasai subjek Sains dan Matematik. Justeru, ini menunjukkan peranan guru di dalam penyampaian PdPc sedikit sebanyak mempengaruhi keputusan pelajar berkaitan bidang STEM.

Grasha (1994) menyatakan bahawa gaya pengajaran guru amat penting dalam mewujudkan iklim pembelajaran yang ideal di dalam bilik darjah. Oleh itu, adalah penting untuk mengenalpasti gaya pengajaran yang diamalkan dalam kalangan pensyarah subjek sains di kolej matrikulasi KPM agar penyampaian PdPc pensyarah dapat memberikan persepsi dan pengaruh yang positif dalam kalangan pelajar terhadap bidang STEM.

\section{SOROTAN LITERATUR}

\section{Definisi Gaya Pengajaran}

Fischer dan Fischer (1979) mendefinisikan gaya pengajaran sebagai merujuk kepada pendekatan yang digunakan di dalam bilik darjah yang lazimnya terdiri daripada penggunaan beberapa kaedah pengajaran yang konsisten. Menurut Grasha (1994), gaya pengajaran merupakan pola tertentu berkaitan keperluan, kepercayaan, dan tingkah laku yang dipamerkan oleh guru di dalam bilik darjah. Selain itu, gaya pengajaran juga membawa maksud sebagai kaedah yang digunapakai oleh guru ketika mengendalikan aktiviti pengajaran dan pembelajaran di dalam kelas (Hussain \& Ayub, 2012). 


\section{Gaya Pengajaran Grasha}

Grasha (1994) mengklasifikasikan gaya pengajaran kepada gaya pengajaran pakar, gaya pengajaran formal, gaya pengajaran model peribadi, gaya pengajaran fasilitator dan gaya pengajaran delegator.

Gaya pengajaran pakar merujuk kepada guru yang memiliki pengetahuan dan kepakaran yang diperlukan oleh pelajar. Bagi mengukuhkan status sebagai pakar dalam kalangan pelajar, guru ini akan cenderung untuk menunjukkan pengetahuannya secara terperinci dan sentiasa mencabar pelajar untuk meningkatkan kompetensi mereka. Guru ini juga berhati - hati dalam menyampaikan maklumat dan akan memastikan pelajar sentiasa bersedia.

Bagi guru yang memiliki gaya pengajaran autoriti formal pula, mereka amat prihatin kepada pelajar dengan memberikan maklumbalas yang positif dan negatif, menetapkan matlamat pembelajaran, dan juga peraturan kepada pelajar. Mereka turut mementingkan cara yang 'betul, diterima dan standard' dalam melakukan sesuatu.

Pada masa yang sama, gaya pengajaran model peribadi merujuk kepada guru yang mengajar berasaskan kepada teladan dirinya sendiri. Mereka akan memberi tunjuk ajar secara langsung dan menggalakkan pelajar mencontohinya.

Gaya pengajaran fasilitator pula, memperlihatkan interaksi guru dan pelajar sebenar. Guru akan membimbing pelajar dengan bertanyakan soalan, meneroka pilihan- pilihan yang ada, dan menggalakkan pelajar membuat keputusan yang betul. Gaya ini juga memperlihatkan guru lebih cenderung untuk membimbing pelajar menjalankan aktiviti berasaskan projek dan memberi galakkan sepenuhnya kepada mereka.

Akhir sekali, gaya pengajaran delegator merujuk kepada guru yang menitikberatkan pembangunan kapasiti kendiri pelajar. Pelajar akan digalakkan untuk menjalankan pembelajaran kendiri seperti kerja projek dan guru akan bertindak sebagai sumber rujukan.

Gaya pengajaran Grasha ini telah menjadi asas kepada banyak kajian terutamanya dalam bidang pendidikan di seluruh dunia. Dalam bidang pendidikan Bahasa Inggeris, Faruji (2012) telah menjalankan kajian tentang gaya pengajaran di Institut Bahasa Inggeris di Iran. Beliau mencadangkan bahawa kebanyakan guru mengamalkan gaya pengajaran autoriti formal dan gaya ini didominasi oleh guru lelaki berusia muda. Pada masa yang sama, Sheikh dan Mahmood (2014) melaporkan dapatan yang serupa di mana kebanyakan guru bahasa Inggeris dalam kajian mereka di Pakistan mengamalkan gaya pengajaran autoriti formal berbanding gaya pengajaran yang lain. Selain itu, mereka juga melaporkan motivasi pelajar didapati meningkat dengan gaya pengajaran delegator daripada guru.

Karamustafaoğlu, Çakır dan Celep (2015) telah menjalankan kajian tentang hubungan antara sikap guru sains terhadap teknologi dengan amalan gaya pengajaran mereka. Dalam kajian ini di dapati kebanyakan guru sains mengamalkan gaya pengajaran pakar dan diikuti dengan gaya pengajaran delegator berbanding dengan gaya pengajaran yang lain. Pada masa yang sama, terdapat korelasi yang postif antara sikap guru sains terhadap teknologi dengan semua jenis gaya pengajaran. Selari dengan dapatan ini, Manalo (2017) mendapati gaya pengajaran dominan yang diamalkan dalam kalangan guru sains di Filipinan adalah gaya pengajaran pakar. Beliau juga melaporkan tedapat korelasi positif yang sederhana antara gaya pengajaran guru dengan pencapaian pelajar.

Di Malaysia, kajian oleh Ainonmadiah, Awanis, Norhana, Juliana dan Siti Noor (2017) melaporkan gaya pengajaran yang paling dominan dalam kalangan guru di Bachok, Kelantan adalah gaya model personal. Kajian ini turut melaporkan tidak terdapat hubungan signifikan antara gaya pengajaran guru dan tahap ponteng pelajar di sekolah menengah. Zamri, Nik Mohd Rahimi dan Juliawati (2009) pula menjalankan kajian terhadap gaya pengajaran guru bahasa di daerah Hulu Langat, Selangor dan mendapati tiga gaya pengajaran yang kerap diamalkan oleh para guru adalah gaya pengajaran model personal, gaya pengajaran fasilitator dan gaya pengajaran delegator.

Dalam bidang sains dan matematik pula, kajian oleh Mohd Eizuan, Noor Shah dan Mohd Uzi (2012) pada pelajar tingkatan 4 di daerah Batang Padang, Perak mendapati gaya pengajaran yang dominan dalam kalangan guru matematik adalah gaya pengajaran pakar dan 
delegator. Mereka juga melaporkan terdapat hubungan korelasi yang sangat lemah antara tahap kemahiran penaakulan saintifik pelajar dengan gaya pengajaran guru. Selain itu, Azilah (2010) dalam tesis sarjana beliau melaporkan bahawa gaya pengajaran yang cenderung diamalkan dalam kalangan guru matematik di Kota Tinggi Johor adalah gaya pengajaran model peribadi, diikuti dengan gaya pengajaran delegator, pakar, fasilitator dan akhir sekali gaya pengajaran autoriti formal. Beliau turut melaporkan terdapat hubungan yang signifikan antara gaya penjaran dengan personaliti guru. Selari dengan dapatan daripada Azilah (2010), Canisius dan Aziz (2012) juga melaporkan gaya pengajaran model peribadi merupakan gaya yang kerap diamalkan dalam kalangan guru sains dan matematik di Penampang, Sabah. Namun begitu, gaya yang paling kurang popular adalah gaya pengajaran delegator.

Terdapat juga kajian berkaitan gaya pengajaran yang diamalkan dalam kalangan pensyarah di peringkat pengajian tinggi seperti yang dijalankan oleh Abdull Sukor, Nurahimah, Izam, Rafisah dan Nur Fatirah (2014) di Universiti Utara Malaysia. Mereka melaporkan majoriti pensyarah mengamalkan gaya pengajaran model personal diikuti dengan gaya pengajaran pakar. Namun begitu, gaya pengajaran delegator mendapat skor min paling rendah berbanding gaya lain. Kajian di Universiti Pendidikan Sultan Idris pula mendapati gaya pengajaran yang dominan diamalkan oleh pensyarah matematik adalah gaya pengajaran pakar dan delegator (Amalina, Nor'ain, \& Norashiqin, 2012). Kajian ini turut melaporkan tiada hubungan signifikan antara tahap kemahiran penaakulan saintifik dengan gaya pengajaran pensyarah. Manakala kajian di Universiti Kebangsaan Malaysia pula melaporkan gaya pengajaran yang sering menjadi amalan pensyarah adalah gaya pengajaran pakar, fasilitator dan delegator (Ruslin \& Zalizan, 2010).

Selain itu, Nur Liyana dan Zakiah (2017) telah menjalankan kajian bagi mengenalpasti hubungan antara motivasi pelajar dengan gaya pengajaran guru di sekolah menengah di Kulai, Johor. Dapatan mereka mencadangkan, gaya pengajaran guru yang paling diminati pelajar adalah gaya pengajaran model personal. Penyelidik juga melaporkan terdapat hubungan yang sederhana antara gaya pengajaran guru dan motivasi pelajar.

\section{PERNYATAAN MASALAH}

Bagi mengekang pola kemerosotan pelajar dalam bidang STEM, adalah sangat penting bagi warga pendidik dalam bidang sains untuk menarik semula minat pelajar dalam bidang ini. Transisi pelajar daripada sekolah menengah ke universiti merupakan saat yang kritikal bagi menentukan hala tuju pelajar di dalam bidang STEM. Maka, peranan pensyarah sains di kolej pra-universiti adalah sangat penting bagi memupuk dan mengekalkan minat pelajar dalam bidang STEM. Fatin et al. (2014) menyatakan bahawa kaedah dan amalan PdPc memberi kesan langsung kepada persepsi dan kerisauan pelajar dalam menguasai subjek Sains dan Matematik. Hal ini pada masa yang sama menunjukkan peranan dan penyampaian PdPc guru memberi kesan langsung dalam mempengaruhi minat pelajar dalam bidang STEM. Justeru, sebagai langkah permulaan, adalah wajar untuk mengenalpasti gaya pengajaran yang diamalkan dalam kalangan pensyarah sains di kolej pra-universiti dan secara tidak langsung dapatan daripada kajian ini dapat menjadi asas kepada kajian - kajian yang akan menyumbang kepada peningkatan minat dan motivasi pelajar dalam bidang STEM. Hasil daripada tinjauan literatur juga mendapati kurang kajian yang dijalankan terhadap gaya pengajaran pensyarah di kolej pra-universiti, lantas ini menjadikan kajian ini relevan untuk mengisi kelompangan maklumat dalam pengetahuan sedia ada. 


\section{OBJEKTIF KAJIAN}

Kajian ini bertujuan untuk mengkaji objektif berikut:

a. Mengenalpasti pola gaya pengajaran Grasha (pakar, autoriti formal, model personal, fasilitator dan delegator) yang diamalkan dalam kalangan pensyarah subjek sains di kolej pra-universiti di Pulau Pinang.

b. Mengenalpasti hubungan antara gaya pengajaran pensyarah subjek sains dengan pengalaman mengajar.

c. Mengenalpasti hubungan antara gaya pengajaran pensyarah subjek sains dengan kelayakan ikhtisas.

d. Mengenalpasti perbezaan gaya pengajaran pensyarah subjek sains berdasarkan jantina.

\section{METODOLOGI}

\section{Reka bentuk Kajian}

Kajian ini menggunakan pendekatan kuantitatif dengan reka bentuk kajian tinjauan.

\section{Populasi dan Sampel Kajian}

Populasi kajian merupakan semua pensyarah Jabatan Sains di kolej pra-universiti di Pulau Pinang. Jumlah keseluruhan pensyarah yang berdaftar dalam sistem adalah seramai 94 orang. Memandangkan saiz populasi yang kurang daripada 100, Gay dan Airasian (2003) menyatakan keseluruhan populasi perlu dijadikan sampel. Walaubagaimanapun, terdapat kekangan yang melibatkan tempoh pentadbiran soal selidik yang singkat. Kekangan tersebut termasuklah pensyarah yang bercuti kerana sakit dan juga berkursus di luar kolej. Maka tidak semua pensyarah terlibat dalam soal selidik ini. Maka jumlah keseluruhan responden yang terlibat adalah seramai 67 orang. Oleh itu dapatan kajian ini hanyalah terhad untuk mewakili populasi kolej pra-universiti di Pulau Pinang sahaja.

\section{Instrumen Kajian}

Kajian ini menggunapakai instrumen soal selidik yang telah diadaptasi daripada Soal Selidik Gaya Pengajaran Grasha-Riechmann 1994. Soal selidik ini mempunyai 5 konstruk yang merujuk kepada 5 jenis gaya pengajaran yang berlainan (pakar, autoriti formal, model personal, fasilitator dan delegator). Soal selidik ini mempunyai 40 item secara keseluruhan dan setiap konstruk mempunyai lapan item. Bagi menjawab persoalan kajian (soalan kajian ii, iii, dan iv), maklumat demografi responden seperti pengalaman mengajar, kelayakan ikhtisas dan jantina turut disertakan dalam borang soal selidik ini. Bagi menentukan kesahan instrument ini, dua orang pakar telah dilantik sebagai penilai. Pakar-pakar tersebut merupakan pensyarah biologi berpengalaman di kolej matrikulasi. Kajian rintis telah dijalankan kepada 30 orang responden bagi menentukan kebolehpercayaan instrumen ini. Analisis menggunakan perisian SPSS (Statistical Package for the Social Sciences) memberikan nilai alpha Cronbach 0.870 bagi kajian sebenar.

\section{Analisis Data}

Kajian ini menggunakan perisaian SPSS untuk menganalisis data tidak selanjar dan data yang diperoleh adalah berbentuk diskrit. Ujian non-parametrik juga dilakukan kerana skala yang digunakan dalam soal selidik adalah merupakan skala ordinal iaitu menggunakan skala Likert lima mata. Analisis mod telah digunakan bagi menjawab objektif kajian pertama iaitu mengenalpasti pola gaya pengajaran Grasha yang diamalkan dalam kalangan pensyarah 
subjek sains di kolej pra-universiti di Pulau Pinang. Seterusnya, analisis korelasi Spearman'srho pula digunakan untuk menjawab objektif kajian kedua dan ketiga iaitu mengenalpasti hubungan antara gaya pengajaran pensyarah subjek sains dengan pengalaman mengajar dan mengenalpasti hubungan antara gaya pengajaran pensyarah subjek sains dengan kelayakan ikhtisas. Akhir sekali, analisis ujian Mann-Whitney $U$ telah digunakan untuk menjawab objektif kajian yang terakhir iaitu mengenalpasti perbezaan gaya pengajaran pensyarah subjek sains berdasarkan jantina.

\section{DAPATAN KAJIAN DAN PERBINCANGAN}

Berdasarkan analisis data yang telah dibuat, kesemua persoalan kajian dapat dijawab dengan baik. Catatan mod telah digunakan untuk mengetahui gaya pengajaran yang paling dominan kerana data yang digunakan merupakan data tidak selanjar. Berdasarkan Jadual 1 dibawah, gaya pengajaran pakar merupakan gaya pengajaran yang paling dominan dalam kalangan pensyarah subjek sains dengan catatan mod yang paling tinggi iaitu 36.00, diikuti dengan gaya pengajaran model peripadi (34.00), fasilitator (32.00), delegator (30.00) dan autoriti formal (28.00).

Ini menunjukkan bahawa pensyarah subjek sains di kolej pra-universiti di Pulau Pinang lebih cenderung untuk menggalakkan persaingan dan mencabar pemikiran pelajar yang mana dapat mempersiapkan para pelajar ke alam universiti yang lebih mencabar dan mempunyai banyak persaingan. Seterusnya, gaya pengajaran yang paling kurang digunakan oleh pensyarah subjek sains adalah gaya pengajaran autoriti formal dengan catatan mod yang terendah iaitu 28.00. Ini membuktikan bahawa pensyarah subjek sains di kolej pra-universiti di Pulau Pinang kurang gemar untuk menyampaikan pembelajaran secara sehala berbentuk kuliah dengan tujuan memberi ilmu sahaja.

Jadual 1 Ringkasan Dapatan Persoalan Kajian 1

\begin{tabular}{cc}
\hline Gaya Pengajaran & Mod \\
\hline Pakar & 36.00 \\
Autoriti Formal & 28.00 \\
Model Peribadi & 34.00 \\
Fasilitator & 32.00 \\
Delegator & 30.00 \\
\hline
\end{tabular}

Merujuk kepada Jadual 2, dapat dilihat bahawa gaya pengajaran pensyarah lelaki dan pensyarah perempuan tidak mempunyai beza yang ketara. Walaupun pensyarah lelaki menunjukkan lebih dominan kepada gaya pengajaran pakar dengan catatan 34.44 dan pensyarah perempuan pula menunjukkan dominan kepada gaya pengajaran model personal dengan catatan 34.65 , namun perbezaannya hanyalah sedikit.

Jadual 2 Gaya Pengajaran Mengikut Jantina

\begin{tabular}{ccc}
\hline Gaya Pengajaran & Lelaki & Perempuan \\
\hline Pakar & 34.44 & 34.55 \\
Autoriti Formal & 29.44 & 29.08 \\
Model personal & 33.81 & 34.65 \\
Fasilitator & 33.38 & 33.53 \\
Delegator & 31.06 & 30.92 \\
\hline
\end{tabular}


Analisis pekali korelasi Spearman's-rho telah dilakukan untuk mengenalpasti hubungan antara gaya pengajaran dengan pengalaman mengajar. Analisis ini digunakan untuk data yang tidak selanjar. Berdasarkan Jadual 2, hubungan yang sangat lemah atau hampir tiada hubungan yang signifikan antara gaya pengajaran dengan pengalaman mengajar $(\mathrm{r}=0.089, p$ $>0.05)$.

Jadual 3 Ringkasan Dapatan Persoalan Kajian 2

\begin{tabular}{ccc}
\hline Hubungan Pembolehubah & Korelasi, $\boldsymbol{r}$ & Signifikan, $\boldsymbol{p}$ \\
\hline $\begin{array}{c}\text { Gaya Pengajaran dengan } \\
\text { pengalaman mengajar }\end{array}$ & 0.089 & 0.473 \\
\hline
\end{tabular}

Seterusnya, analisis pekali korelasi Spearman's-rho juga telah dilakukan untuk menjawab persoalan kajian yang ketiga iaitu mengenalpasti hubungan antara gaya pengajaran dengan kelayakan ikhtisas. Merujuk kepada Jadual 4, dapatan kajian menunjukkan bahawa hubungan yang sangat lemah atau hampir tiada hubungan yang signifikan antara gaya pengajaran dengan kelayakan ikhtisas $(r=0.171, p>0.05)$.

Jadual 4 Ringkasan Dapatan Persoalan Kajian 3

\begin{tabular}{ccc}
\hline Hubungan Pembolehubah & Korelasi, $\boldsymbol{r}$ & Signifikan, $\boldsymbol{p}$ \\
\hline $\begin{array}{c}\text { Gaya Pengajaran dengan } \\
\text { kelayakan ikhtisas }\end{array}$ & 0.193 & 0.119 \\
\hline
\end{tabular}

Bagi menjawab persoalan kajian yang terakhir, ujian Mann-Whitney U telah dilakukan bagi data yang tidak selanjar. Berdasarkan Jadual 5, dapatan kajian menunjukkan tiada perbezaan signifikan antara pensyarah lelaki $(\mathrm{Md}=160.00, \mathrm{n}=16)$ dan pensyarah perempuan $(\mathrm{Md}=$ $162.00, \mathrm{n}=51), \mathrm{U}=393.50, \mathrm{Z}=-0.213, p>0.05$ dengan nilai kesan saiz yang sangat rendah $=0.03$. Oleh itu, hipotesis nol gagal ditolak. Ini bermakna tiada perbezaan signifikan antara gaya pengajaran pensyarah subjek sains berdasarkan jantina. Dapatan ini menunjukkan bahawa gaya pengajaran pensyarah sains tidak dipengaruhi oleh jantina.

Jadual 5 Ringkasan Dapatan Persoalan Kajian 4

\begin{tabular}{ccccccc}
\hline & Jantina & Median & $\begin{array}{c}\text { Nilai } \\
\mathbf{U}\end{array}$ & $\begin{array}{c}\text { Nilai } \\
\mathbf{Z}\end{array}$ & $\begin{array}{c}\text { Kesan } \\
\text { saiz }\end{array}$ & $\begin{array}{c}\text { Nilai } \\
\text { Signifikan, } \\
\mathbf{p}\end{array}$ \\
\hline \multirow{2}{*}{$\begin{array}{c}\text { Gaya } \\
\text { Pengajaran }\end{array}$} & Lelaki & 160.00 & & & & \\
\cline { 2 - 6 } & Perempuan & 162.00 & & -0.213 & 0.03 & 0.831 \\
\hline
\end{tabular}

\section{KESIMPULAN}

Sebagai kesimpulan, terdapat variasi gaya pengajaran pensyarah subjek sains di kolej prauniversiti di Pulau Pinang. Berdasarkan dapatan kajian, gaya pengajaran pakar merupakan gaya pengajaran yang paling dominan di kalangan pensyarah subjek sains. Ini membuktikan, pensyarah sains di kolej pra-universiti di Pulau Pinang, lebih cenderung untuk menggalakkan persaingan dan mencabar pemikiran pelajar. Selain itu, didapati tiada perhubungan dapat dikesan antara gaya pengajaran dengan pengalaman mengajar mahupun dengan kelayakan ikhtisas. Hal ini dapat disimpulkan bahawa gaya pengajaran seseorang pensyarah adalah berdasarkan individu itu sendiri dan tiada perkaitan dengan pengalaman mengajar dan 
kelayakan ikhtisas. Selain itu, dapatan kajian juga menunjukkan tiada perbezaan antara gaya pengajaran dengan jantina.

\section{RUJUKAN}

Abdull Sukor, S., Nurahimah, M. Y., Izam, M. G., Rafisah, H. O., \& Nur Fatirah, M. D. (2014). The Relationship between Lecturers' Teaching Style and Students' Academic Engagement. Procedia - Social and Behavioral Sciences, 118, 10-20. Elsevier BV.

Ainonmadiah, Mohd. N., Awanis, M., Norhana, Md. S., Juliana, B., \& Siti Noor, I. (2017). Hubungan Antara Gaya Pengajaran Guru Dengan Tahap Ponteng Sekolah Menengah Di Daerah Bachok, Kelantan. Proceedings of the ICECRS, 1(1). Muhammadiyah University Sidoarjo.

Amalina, I., Nor'ain, Mohd. T., \& Norashiqin, Mohd. I. (2012). Hubungan Antara Tahap Kemahiran Penaakulan Saintifik Dan Stail Pengajaran Pensyarah Dalam Kalangan Pelajar Matematik Di Universiti Pendidikan Sultan Idris. Prosiding Kolokium Kebangsaan Pasca Siswazah Sains dan Matematik.

Azilah, A. R. (2010). Hubungan Antara Personaliti Dan Gaya Pengajaran Guru Dengan Pencapaian Matematik Pmr Satu Kajian Di Sekolah Menengah Daerah Kota Tinggi. (Master Thesis). Universiti Teknologi Malaysia. Skudai, Malaysia.

Canisius, C., \& Aziz, N. (2012). Gaya Pengajaran Grasha Dalam Kalangan Guru-Guru Sains Dan Matematik Di Sekolah Menengah Di Daerah Penampang Sabah. (Bachelor's Thesis). Universiti Teknologi Malaysia. Skudai, Malaysia.

Faruji, L. F. (2012). International Journal of Social Sciences and Education Teachers' Teaching Styles at English Language Institutes in Iran. International Journal of Social Sciences and Education, 2 (1 January 2012), 364-373.

Fatin, A. P., Mohd Salleh, A., Mohammad Bilal, A., \& Salmiza, S. (2014). Faktor Penyumbang Kepada Kemerosotan Penyertaan Pelajar dalam Aliran Sains: Satu Analisis Sorotan Tesis. Sains Humanika, 2(4), 63-71. UTM Press.

Fischer, B., \& Fischer, L. (1979). Styles in teaching \& learning. Educational Leadership, 36, 245-254.

Gay, L.R., \& Airasian, P. (2003). Educational Research: Competencies for Analysis and Application. ( $7^{\text {th }}$ ed.). Upper Saddle River, NJ: Pearson Education.

Grasha, A. F. (1994). A Matter of Style: The Teacher as Expert, Formal Authority, Personal Model, Facilitator, and Delegator (Vol. 42). Heldref Publications.

Hussain, N., \& Ayub, N. (2012). Learning Styles of Students and Teaching Styles of Teachers in Business Education: A Case Study of Pakistan. Procedia - Social and Behavioral Sciences, 69, 1737-1740. Elsevier BV.

Karamustafaoğlu, S., Çakır, R., \& Celep, A. (2015). Relationship between the Attidutes of Science Teachers towards Technology and Their Teaching Styles. Participatory Educational Research (PER), 2(3), 67-78. Retrieved from http://www.partedres.com

Manalo, K. J. C. (2017). Science Teachers' Teaching Styles, Students' Learning Styles and Their Academic Performance. International Journal of Social Science and Humanities Research, 5, 397-408. Retrieved from www.researchpublish.com

Mohd Eizuan, A. H., Noor Shah, S., \& Mohd Uzi, D. (2012). Kemahiran Penaakulan Saintifik (KPS) Dalam Kalangan. Jurnal Pendidikan Sains \& Matematik Malaysia, 2(2), 1-10.

Nur Liyana, M. I., \& Zakiah, M. A. (2017). Relationship Between Motivation and Teachers' Teaching Style Among Secondary School Students’ In Kulai. Man In India, 97(12), 299-307.

Pelan Pembangunan Pendidikan Malaysia 2013-2025. (2013). Retrieved from www.moe.gov.my

Ruslin, A., \& Zalizan, M. J. (2010). Teaching and learning styles in higher education institutions: Do they match? Procedia - Social and Behavioral Sciences (Vol. 7, pp. 680-684). Elsevier Ltd.

Salhani, I. (2019, March 12). Jumlah Pelajar Mengambil STEM Kian Merosot. BH Online, Retrived from https://www.bharian.com.my/berita/pendidikan/2019/03/540193/jumlah-pelajarmengambil-stem-kian-merosot

Sheikh, A., \& Mahmood, N. (2014). Effect of Different Teaching Styles on Students' Motivation Towards English Language Learning at Secondary Level. Science International (Lahore), 26(2), 825-830. Retrieved from https://www.researchgate.net/publication/334626377

Wan Faizal, I. (2019, September 27). Kerajaan Risau Penurunan Pelajar Pilih Aliran STEM. BH Online, Retrived from https://www.bharian.com.my/berita/nasional/2019/09/611487/kerajaanrisau-penurunan-pelajar-pilih-aliran-stem 
JURNAL PENDIDIKAN SAINS \& MATEMATIK MALAYSIA

VOL 9 NO.2 DEC 2019 / ISSN 2232-0393 / eISSN 2600-9307

Zamri, M., Nik Mohd Rahimi, N. Y., \& Juliawati, I. (2009). Perbandingan Gaya Pengajaran Guru Bahasa Melayu dan Guru Bahasa Inggeris. Jurnal Pendidikan Malaysia, (34(1)), 67-92. 